\title{
Fontes de lipídeos na dieta de búfalas lactantes: consumo, digestibilidade e $\mathrm{N}$-uréico plasmático
}

\author{
Ronaldo Lopes Oliveira ${ }^{1}$, Adriana Regina Bagaldo ${ }^{2}$, Márcio Machado Ladeira ${ }^{3}$, Marco Aurélio \\ Alves de Freitas Barbosa ${ }^{4}$, Renata Lopes de Oliveira ${ }^{5}$, Soraya Maria Palma Luz Jaeger ${ }^{6}$
}

\author{
${ }^{1}$ DPA/UFBA, Salvador-BA. \\ 2 Bolsista PRODOC/DCR - FAPESB/CNPq, DPA/UFBA, Salvador-BA. \\ ${ }^{3}$ DZO/UFLA, Lavras-MG. \\ ${ }^{4}$ DZO/UEL, Londrina-PR. \\ ${ }^{5}$ Curso de Zootecnia da UPIS, Brasília-DF. \\ ${ }^{6}$ CCAA/UFRB, Cruz das Almas-BA.
}

RESUMO - Os efeitos da suplementação de fontes lipídicas sobre o consumo, a digestibilidade dos nutrientes e o $\mathrm{N}$-uréico plasmático foram avaliados em 12 búfalas lactantes, em três quadrados latinos simultâneos, cada um com quatro animais, quatro períodos e quatro dietas contendo uma das fontes de lípideo estudadas (sem lipídeo adicional; grão de soja; óleo de soja ou caroço de algodão). O período experimental foi de 84 dias, com quatro períodos de 21 dias, divididos em 14 dias para a adaptação e 7 para coleta. A dieta foi fornecida à vontade, duas vezes ao dia, na forma de mistura completa Nos dias de coleta de cada período, os alimentos fornecidos e as sobras foram pesados e amostrados para análise bromatológica. Amostras de fezes foram coletadas diretamente no reto dos animais para estimativa da produção de matéria seca fecal, utilizando-se a fibra em detergente neutro indigestível como indicador, e para o cálculo de digestibilidade aparente. Os consumos de matéria seca, proteína bruta, fibra em detergente neutro e fibra em detergente ácido foram semelhantes entre as dietas. Os consumos de extrato etéreo e nutrientes digestíveis totais (NDT) foram maiores para a dieta com óleo de soja. Os coeficientes de digestibilidade de matéria seca, proteína bruta e carboidratos não-fibrosos e as concentrações de N-uréico plasmático foram semelhantes entre as dietas. A utilização das fontes de lipídeos nas dietas de búfalas em lactação não influenciou o consumo e coeficiente de digestibilidade da matéria seca. Entretanto, as digestibilidades do extrato etéreo da dieta com grão de soja e das frações fibrosas da dieta com caroço de algodão foram as mais baixas.

Palavras-chave: bubalinos, caroço de algodão, grão de soja, óleo de soja

\section{Effects of dietary fat sources on intake, nutrient digestibility and plasma urea nitrogen for lactating water buffaloes}

\begin{abstract}
The effects of fat sources on intake, nutrient digestibility and plasma urea nitrogen were evaluated in lactating water buffalo. Twelve females were randomly distributed into four treatments: without additional lipid, soybean grain, soybean oil and cottonseed. The experimental period was 84 days, with four 21-day periods (14 days for diet adaptation and 7 for collection). Diets were offered ad libitum, twice daily, as total mixed ration. At the collecting period, samples of food and surpluses were weighed and collected for chemical analysis. Faeces samples were collected from rectum for estimation of faecal dry matter production, using indigestible neutral detergent fiber as indicator, and consequently for apparent digestibility calculations. Dry matter (DM), crude protein (CP), neutral detergent fiber (NDF) and acid detergent fiber (ADF) intakes were similar between treatments. The ether extract intake was higher for soybean oil diet. The same behavior was observed for the total digestible nutrient (TDN) intake for this diet, since the previous diet showed higher TDN percentage. The digestibility coefficient for DM, CP, non-fibrous carbohydrate, and serum urea nitrogen were similar between diets. Different lipid sources in the diets for lactating water buffalo did not influence the DM intake and digestibility coefficient, when ether extract content was under $5 \%$. However, the ether extract and fibrous fractions digestibility coefficients in diets with soybean grain and cottonseed were the lowest.
\end{abstract}

Key Words: buffaloes, cottonseed, soybean grain, soybean oil

\section{Introdução}

O interesse de profissionais e produtores em melhorar a eficiência de utilização de nutrientes pelos ruminantes tem incentivado estudos para avaliação de alimentos utilizando dietas balanceadas e considerando as múltiplas inter-relações dos microrganismos ruminais $\times$ hospedeiro. 
O consumo e a digestibilidade dos nutrientes podem ser afetados pelos níveis de lipídeos na dieta. A redução na ingestão de matéria seca está relacionada ao controle quimiostático do consumo e a queda na digestibilidade da fibra está relacionada à formação de uma barreira física nas partículas que dificulta o ataque microbiano e a ação tóxica do ácido graxo insaturado sobre certas espécies de microrganismos (Palmquist, 1991). Quando administrados ácidos graxos insaturados para ruminantes, os microrganismos os hidrolisam e promovem a saturação com hidrogênio, processo chamado biohidrogenação. Estas reações são realizadas para a auto-proteção dos microrganismos, uma vez que os efeitos maléficos dos ácidos graxos saturados é menor que o dos insaturados.

Por outro lado, mesmo com o processo de biohidrogenação, níveis elevados de lipídeos podem reduzir o consumo e a digestibilidade, motivo pelo qual as concentrações de extrato etéreo na matéria seca da dieta de ruminantes não é superior a 7\% (Palmquist \& Jenkins, 1980). Segundo Palmquist (1989), os benefícios da utilização de lipídeos em dietas para animais em lactação estão relacionados ao alto valor energético dessas dietas (6 Mcal ELl $/ \mathrm{kg}$ ). Essa vantagem pode ser explorada de várias formas: aumentando a densidade calórica da dieta e o consumo de energia e realizando o balanço mais adequado entre carboidratos fibrosos e nãofibrosos para otimização do consumo de fibra e energia digestível (Bauman \& Lock, 2006).

Com o aumento na produção de soja, algodão e outras oleaginosas no Brasil Central e sul do Pará e Maranhão, além de outras fontes lipídicas na Região Norte, os produtores de búfalos podem utilizar outras fontes energéticas para seus animais. Nawaz et al. (2001) e Abdullah et al. (2001), ao trabalharem com níveis de lipídeos na alimentação de búfalas lactantes no Paquistão, observaram aumento da produção de leite corrigida para gordura e redução no consumo e na digestibilidade da matéria seca à medida que elevaram o nível lipídico da dieta.

Objetivou-se com este trabalho avaliar fontes de lipídeos para búfalas em lactação, por meio do consumo e da digestibilidade dos nutrientes e do N-uréico plasmático.

\section{Material e Métodos}

O experimento foi realizado na Fazenda Lagoa Bonita, Campus Rural das Faculdades Integradas UPIS, localizada em Planaltina, Distrito Federal, utilizando-se 12 búfalas em lactação, multíparas e com produção média diária de leite de $6,5 \mathrm{~kg}$ e peso vivo de $683 \pm 17 \mathrm{~kg}$.

Os animais foram distribuídos aleatoriamente em três quadrados latinos, com quatro períodos e quatro dietas com uma das fontes de lipídeo em estudo: sem lipídeo adicional; grão de soja; óleo de soja ou caroço de algodão. Utilizou-se a silagem de milho como volumoso, na proporção de 70 e $75 \%$ da MS da dieta (Tabela 1). O período experimental foi de 84 dias, composto de quatro subperíodos de 21 dias, divididos em 14 dias para adaptação dos animais às dietas experimentais e 7 dias para coleta.

Os animais foram alojados em baias individuais providas de cochos para ração e suplemento mineral e de bebedouros.

A dieta foi fornecida à vontade, na forma de mistura completa, duas vezes ao dia, com água à vontade. Os animais foram alimentados logo após as ordenhas das $5 \mathrm{~h}$ e das $16 \mathrm{~h}$. A pesagem de sobras foi feita diariamente pela manhã a fim de se ajustar a quantidade de alimento ministrada aos animais, para que deixassem resíduo diário de 10 a $20 \%$ do total fornecido.

Nos sete dias de coleta de cada período experimental, amostras de fezes foram retiradas diretamente da ampola retal dos animais, logo após as ordenhas da manhã e da tarde. Nesses períodos, também foram coletadas amostras dos alimentos fornecidos e das sobras, que foram présecas em estufa com ventilação forçada a $55^{\circ} \mathrm{C}$. Posteriormente, as amostras foram moídas em peneira com crivos de $1 \mathrm{~mm}$ e homogeneizadas para formação de amostras compostas por período e por animal. Essas amostras compostas foram encaminhadas ao Laboratório de Análise de Alimentos das Faculdades Integradas da UPIS para análise dos teores de matéria seca (MS), proteína bruta (PB), extrato etéreo (EE), fibra em detergente ácido (FDA) e cinzas, segundo metodologia descrita pela AOAC (1990), e fibra em detergente neutro (FDN), segundo Van Soest et al. (1991). Os teores de carboidratos não-fibrosos (CNF) foram calculados segundo o NRC (1989), em que $\mathrm{CNF}=100-(\mathrm{FDN}+\mathrm{PB}+\mathrm{EE}+\mathrm{Cinzas})$.

A estimativa da produção de matéria seca fecal foi obtida utilizando-se a fibra em detergente neutro indigestível (FDNi) como indicador interno. Amostras de aproximadamente $5 \mathrm{~g}$ de fezes, sobras e silagem e $10 \mathrm{~g}$ dos alimentos concentrados foram acondicionadas em sacos de náilon e incubadas no rúmen de duas búfalas adultas, por 144 horas, segundo metodologia proposta por Cochran et al. (1986). O material remanescente da incubação foi lavado em água corrente e submetido à extração com detergente neutro, cujo resíduo foi considerado FDNi e utilizado para estimar a produção de MS fecal dos animais, por meio da equação:

Produção de MS fecal $(\mathrm{kg})=[\mathrm{FDNi}(\mathrm{g})$ consumida $] \times$

$$
\text { 100/FDNi (\%) fezes }
$$

A digestibilidade da matéria seca total foi estimada utilizando-se a concentração de FDNi como indicador interno de acordo com a seguinte fórmula: 
Tabela 1 - Composição das dietas experimentais

\begin{tabular}{lcccc}
\hline Ingrediente (\%MS) & \multicolumn{4}{c}{$\% \mathrm{MS}$} \\
\cline { 2 - 5 } & $\begin{array}{c}\text { Sem lipídeo } \\
\text { adicional }\end{array}$ & $\begin{array}{c}\text { Grão de } \\
\text { soja }\end{array}$ & $\begin{array}{c}\text { Óleo de } \\
\text { soja }\end{array}$ & $\begin{array}{c}\text { Caroço de } \\
\text { algodão }\end{array}$ \\
\hline Silagem de milho & 70,00 & 75,00 & 74,72 & 70,83 \\
Milho grão moído & 15,94 & 8,58 & 8,33 & 12,92 \\
Farelo de soja & 12,03 & 1,89 & 12,70 & 11,67 \\
Grão de soja & - & 12,50 & - & - \\
Óleo de soja & - & - & 2,21 & - \\
Caroço de algodão & - & - & - & 2,50 \\
Calcário & 0,31 & 0,31 & 0,31 & 0,33 \\
Fosfato bicálcico & 1,72 & 1,72 & 1,72 & 1,75 \\
\hline Item (\%MS) & & & & \\
\hline Proteína bruta & 11,89 & 12,05 & 11,96 & 12,09 \\
Fibra em detergente & 41,40 & 44,60 & 42,72 & 42,32 \\
neutro & & & & \\
Fibra em detergente & 28,29 & 31,09 & 28,61 & 28,84 \\
ácido & & & & \\
Extrato etéreo & 2,76 & 4,34 & 4,85 & 3,10 \\
Carboidratos & 35,45 & 30,28 & 31,68 & 33,82 \\
não-fibrosos & 8,51 & 8,73 & 8,79 & 8,66 \\
Cinzas & & & & \\
\hline
\end{tabular}

$\operatorname{DMS}(\%)=100-[100 \times($ FDNi consumida $) /($ FDNI fezes $)]$ em que: $\mathrm{DMS}=$ coeficiente de digestibilidade da matéria seca.

Após a análise laboratorial das amostras, foram calculados os consumos e as digestibilidades aparentes de proteína bruta, fibra em detergente neutro, fibra em detergente ácido, extrato etéreo, matéria orgânica e carboidratos não-fibrosos.

O consumo de NDT, em $\mathrm{kg}$, e os teores de nutrientes digestíveis totais (NDT\%) foram calculados segundo Sniffen et al. (1992), pelas seguintes equações: $\mathrm{NDT}=(\mathrm{PB}$ ing. $-\mathrm{PB}$ fecal $)+2,25$ (EE ing. - EE fecal $)+($ CT ing. $-\mathrm{CT}$ fecal $)$ NDT $(\%)=($ Consumo de NDT/Consumo de MS $) \times 100$.

Ao fim de cada período, o sangue foi coletado da veia jugular $(10 \mathrm{~mL})$, primeiramente em jejum e posteriormente em intervalos de 2 horas, sem a restrição alimentar, totalizando quatro amostras por animal por período.

As amostras de sangue foram levadas imediatamente para o Laboratório de Análise de Alimentos do Departamento de Zootecnia da UPIS, onde foram centrifugadas para separação do plasma. O teor de N-uréico foi determinado considerando que a uréia plasmática contém $46 \%$ de nitrogênio. Utilizou-se o protocolo de kits enzimáticos comerciais para as análises laboratoriais, em aparelho espectrofotômetro.

Os dados foram analisados estatisticamente pelo SAEG (UFV, 1997) utilizando-se o teste Tukey a 5\% de probabilidade. Para os teores de N-uréico, adotou-se o esquema de parcelas subdivididas, no qual as dietas eram as parcelas e o tempo após a alimentação, as subparcelas.

\section{Resultados e Discussão}

Os consumos de matéria seca, proteína bruta, fibra em detergente neutro e fibra em detergente ácido (kg/animal/ dia) foram semelhantes entre as dietas $(\mathrm{P}>0,05)$ (Tabela 2). O consumo médio de matéria seca foi de $1,17 \%$ do peso vivo. Consumos maiores foram encontrados em experimentos com búfalos machos: Lorenzoni et al. (1986) observaram consumo médio de matéria seca $2,5 \% \mathrm{PV}$ e Jorge et al. (2006) não observaram diferenças no consumo entre três raças de bubalinos (Jafarabadi, Murraf e Mediterrâneo), cuja média foi de $9,6 \mathrm{~kg} / \mathrm{animal} / \mathrm{dia}$.

A inclusão de óleo em dietas para ruminantes tem sido relacionada à diminuição no consumo de matéria seca, mas a causa desse consumo mais baixo ainda não está bem estabelecida. Freqüentemente, a explicação é relacionada à interferência dos lipídios insaturados sobre a atividade das bactérias Gram-positivas, principais responsáveis pela fermentação da fibra (Cant et al., 1997). Além desses aspectos, as fontes lipídicas testadas poderiam ainda afetar o consumo pela ação direta sobre os hormônios intestinais, pela oxidação de ácidos graxos no fígado e pela aceitabilidade das fontes utilizadas (Allen, 2000). De acordo com essas informações, as fontes lipídicas e seus teores na dieta não ativaram nenhum mecanismo que afetasse o consumo neste trabalho, o que pode ser explicado pelos teores de extrato etéreo das dietas, pois o maior nível foi de $4,85 \%$ para a dieta com óleo de soja, ou seja, abaixo do limite de 7\% preconizado pela literatura (Palmquist \& Jenkins, 1980).

O consumo de matéria seca de fontes lipídicas por diversas espécies de ruminantes tem apresentado diferenças entre estudos observados na literatura. Vilela (1994) avaliou o consumo de matéria seca em \% do PV de vacas lactantes e não observou diferenças no consumo de dietas com 0 a $30 \%$ de caroço de algodão. A inclusão de óleo de soja em até $7,5 \%$ na matéria seca também não afetou o consumo de matéria seca em cabras lactantes (Lana et al., 2007). Silva et al. (2007), no entanto, observaram que o consumo de matéria seca entre cabras mantidas com dietas sem fontes lipídicas adicionais e com $5,0 \%$ de sais de cálcio foi maior que o observado com dietas com $4,5 \%$ de óleo de soja ou $22,42 \%$ de grão de soja.

O consumo de extrato etéreo foi maior para a dieta com óleo de soja (Tabela 2) $(\mathrm{P}<0,05)$. Como essa dieta apresentou o maior teor de extrato etéreo (Tabela 1) e não houve diferença no consumo de MS, essa resposta era esperada. Além disso, a forma física do óleo facilita sua incorporação na ração total, uma vez que os grãos de soja, por possuírem granulometria maior que os outros compo- 
Tabela 2 - Consumos médios de matéria seca e nutrientes por fêmeas bubalinas mantidas com dietas com diferentes fontes de lipídeos

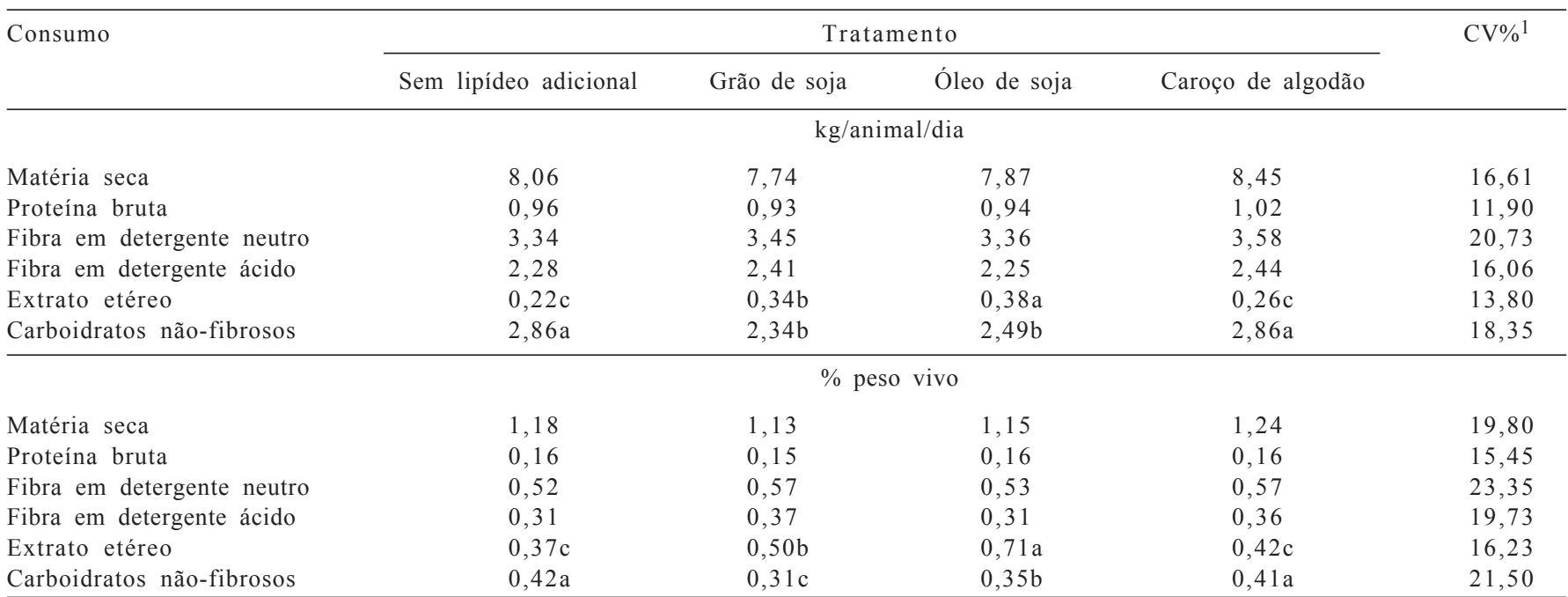

a, b, c Médias nas linhas seguidas por letras iguais não diferem entre si pelo teste Tukey (5\%).

${ }^{1}$ Coeficiente de variação.

nentes da dieta, estão sujeitos à seleção pelo animal no momento do consumo.

A porcentagem de NDT da dieta com óleo de soja foi maior $(\mathrm{P}<0,05)$ que a das dietas sem lipídeo adicional, com grão de soja e com caroço de algodão (Figura 1). Esse fato era esperado, pois parte dos CNF foi substituída pelo extrato etéreo, fração 2,25 vezes mais energética.

Entretanto, o consumo de NDT $(\mathrm{kg} / \mathrm{dia})$ não diferiu $(\mathrm{P}>0,05)$ entre as dietas (Figura 1). Como comentado anteriormente, as fontes lipídicas não influenciaram o consumo de MS, portanto, o fato de o consumo de NDT ter sido semelhante entre as dietas confirma o exposto por Mertens (1992) de que o consumo de matéria seca estaria relacionado ao atendimento das exigências energéticas dos animais. Além disso, apesar de a dieta com óleo de soja ter possibilitado consumo de EE ( $\mathrm{kg} / \mathrm{animal} / \mathrm{dia})$ mais alto, o consumo de CNF foi menor, que deve ter contribuído para as respostas semelhantes para o consumo de NDT ( $\mathrm{kg} / \mathrm{animal} / \mathrm{dia}$ ).

Os coeficientes de digestibilidade de matéria seca, proteína bruta e carboidratos não-fibrosos foram semelhantes entre as dietas (Tabela 3). Um dos efeitos da inclusão de lipídeos em dietas para ruminantes é a diminuição da digestibilidade de nutrientes, principalmente da fibra. As dietas foram elaboradas com teores semelhantes de FDN e pequena variação no extrato etéreo (Tabela 1 ). As dietas sem lipídeo adicional, com grão de soja e com óleo de soja apresentaram coeficientes de digestibilidade de FDN e FDA semelhantes, sugerindo que as condições ruminais mantiveram-se constantes para as três dietas. Neste sentido, Bateman \& Jenkins (1998) mostraram que, se há adequado nível de FDN, o uso de dietas com até 7\% de óleo de soja
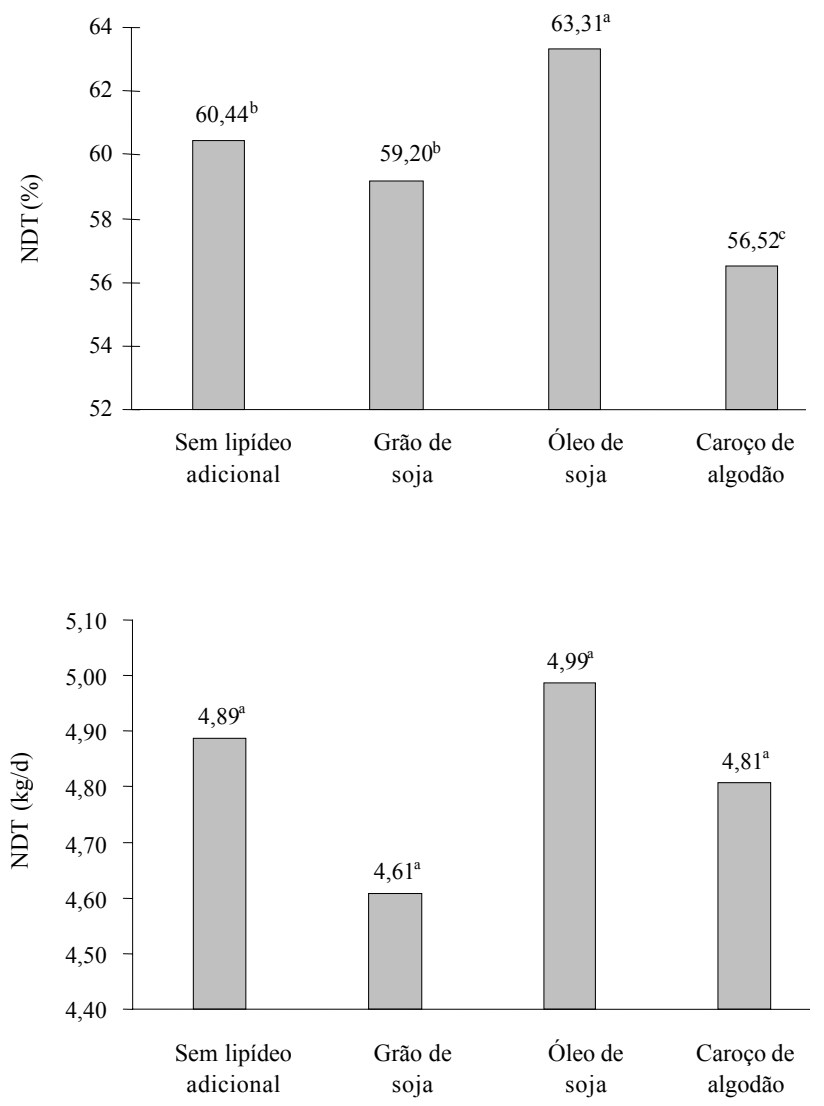

a, b, c Médias nas linhas seguidas por letras iguais não diferem entre si pelo teste Tukey (5\%).

Figura 1 - Porcentagem de nutrientes digestíves totais (NDT\%) nas dietas experimentais e consumo de NDT ( $\mathrm{kg} / \mathrm{dia})$ por búfalas mantidas com dietas com diferentes fontes de lipídeos na dieta. 
Tabela 3 - Digestibilidade (\%) da matéria seca e dos nutrientes de dietas com diferentes fontes de lipídeos fornecidas para fêmeas bubalinas

\begin{tabular}{|c|c|c|c|c|c|}
\hline \multirow[t]{2}{*}{ Item } & \multicolumn{4}{|c|}{ Tratamento } & \multirow[t]{2}{*}{$\mathrm{CV} \%{ }^{1}$} \\
\hline & Sem lipídeo adicional & Grão de soja & Óleo de soja & Caroço de algodão & \\
\hline Matéria seca & 56,51 & 53,28 & 56,06 & 52,35 & 4,48 \\
\hline Proteína bruta & 60,21 & 53,09 & 61,79 & 59,70 & 19,93 \\
\hline Fibra em detergente neutro & $37,48 \mathrm{a}$ & $42,07 \mathrm{a}$ & $40,12 \mathrm{a}$ & $34,31 \mathrm{~b}$ & 16,76 \\
\hline Fibra em detergente ácido & $48,94 \mathrm{a}$ & $50,46 a$ & $47,38 \mathrm{a}$ & $40,84 b$ & 12,95 \\
\hline Extrato etéreo & $88,83 \mathrm{a}$ & $76,81 \mathrm{~b}$ & $90,84 \mathrm{a}$ & $85,74 \mathrm{a}$ & 5,82 \\
\hline Carboidratos não-fibrosos & 83,01 & 88,10 & 80,94 & 81,60 & 7,58 \\
\hline
\end{tabular}

a, b Médias nas linhas seguidas por letras iguais não diferem $(\mathrm{P}<0,05 \%)$ estatisticamente entre si pelo teste Tukey.

${ }^{1}$ Coeficiente de variação.

tem pouco efeito sobre a fermentação ruminal. As menores digestibilidades de FDN e FDA com a dieta com caroço de algodão poderiam ser pelo fato de o grão estar envolto de linter, o que pode dificultar o acesso dos microrganismos e reduzir a digestibilidade.

A digestibilidade do extrato etéreo da dieta com grão de soja foi menor que a da dieta com óleo de soja, o que pode estar associado ao fato de o óleo de soja proporcionar completa disponibilização lipídica no intestino delgado para formação das micelas e absorção. O mesmo não ocorre com o grão de soja, pois foi administrado inteiro e sua matriz pode ter dificultado o acesso da microbiota ruminal e na formação das micelas do intestino delgado.

Silva et al. (2007) também observaram maior coeficiente de digestibilidade do extrato etéreo para dietas com óleo de soja, em comparação ao grão de soja, para cabras em lactação. Ao avaliar o consumo de nutrientes e o coeficiente de digestibilidade em vacas lactantes alimentadas com grão de soja moído no concentrado (0 e 30\%), Pereira et al. (1997) relataram que houve redução no consumo na dieta com $30 \%$ de grão moído e não observaram diferença para a digestibilidade aparente dos nutrientes.

Silva et al. (2007) também relataram que a digestibilidade da FDN também foi menor na dieta contendo óleo de soja em comparação com grão de soja para cabras lactantes. Além de a espécie de ruminante utilizada ter sido diferente, o nível de óleo de soja $(4,50 \%)$ e o teor de extrato etéreo $(6,6 \%)$ na dieta foram superiores aos utilizados neste trabalho, o que pode explicar as diferenças de resultados.

As concentrações de $\mathrm{N}$-uréico plasmático das búfalas, foram semelhantes entre dietas $(\mathrm{P}>0,05)$ (Figura 2$)$. O consumo de $\mathrm{PB}(\mathrm{kg} / \mathrm{dia})$ também foi igual entre as dietas, o que deve ter contribuído para a resposta dos níveis plasmáticos.
Além disso, e de acordo com Huntington \& Archibeque (1999), a energia também influencia os teores de uréia circulante (Figura 1) e, neste trabalho, o consumo de NDT $(\mathrm{kg} / \mathrm{dia})$ também não diferiu entre as dietas.

O catabolismo da proteína degradável no rúmen é responsável pelo pico da uréia plasmática de 4 a 6 horas após a alimentação de vacas leiteiras, e o metabolismo da proteína não-degradável no rúmen contribui para os níveis plasmáticos de uréia durante o dia (Bequette, 1997). Entretanto, neste trabalho, os picos de uréia plasmática foram alcançados 3 e 4 horas após a alimentação, provavelmente em razão da elevada quantidade de silagem de milho na dieta (70-75\%), alimento que possui compostos nitrogenados não-protéicos (NNP) oriundos da fermentação microbiana no silo.

Fergunson et al. (1993) reportaram que a taxa de concepção de vacas leiteiras diminui quando o nível de uréia no sangue é superior a $20 \mathrm{mg} / \mathrm{dL}$ no momento da inseminação. Neste estudo, as médias de N-uréico plasmático nas búfalas mantidas com as dietas com grão de soja $(17,41 \mathrm{mg} / \mathrm{dL}) \mathrm{e}$ com caroço de algodão ( $16,36 \mathrm{mg} / \mathrm{dL})$ estão abaixo do limite relatado pelos autores, enquanto aquelas que receberam as dietas sem lipídeo adicional e com óleo de soja os níveis apresentaram valores superiores $(20,5$ e $21,6 \mathrm{mg} / \mathrm{dL}$ para sem lipídeo adicional e óleo de soja, respectivamente).

$\mathrm{Na}$ maioria das pesquisas em que foram observados altos níveis de uréia plasmática em vacas leiteiras, foram utilizados elevados teores de PB na dieta, 19 a 22\% (Elrod \& Butler, 1993; Barton et al., 1996; Canfield et al., 1990), enquanto as dietas utilizadas neste estudo apresentaram em média $12 \%$ de PB. Como não foi encontrado na literatura o limite da uréia plasmática em búfalas, são necessários mais estudos para determinação desse nível. 

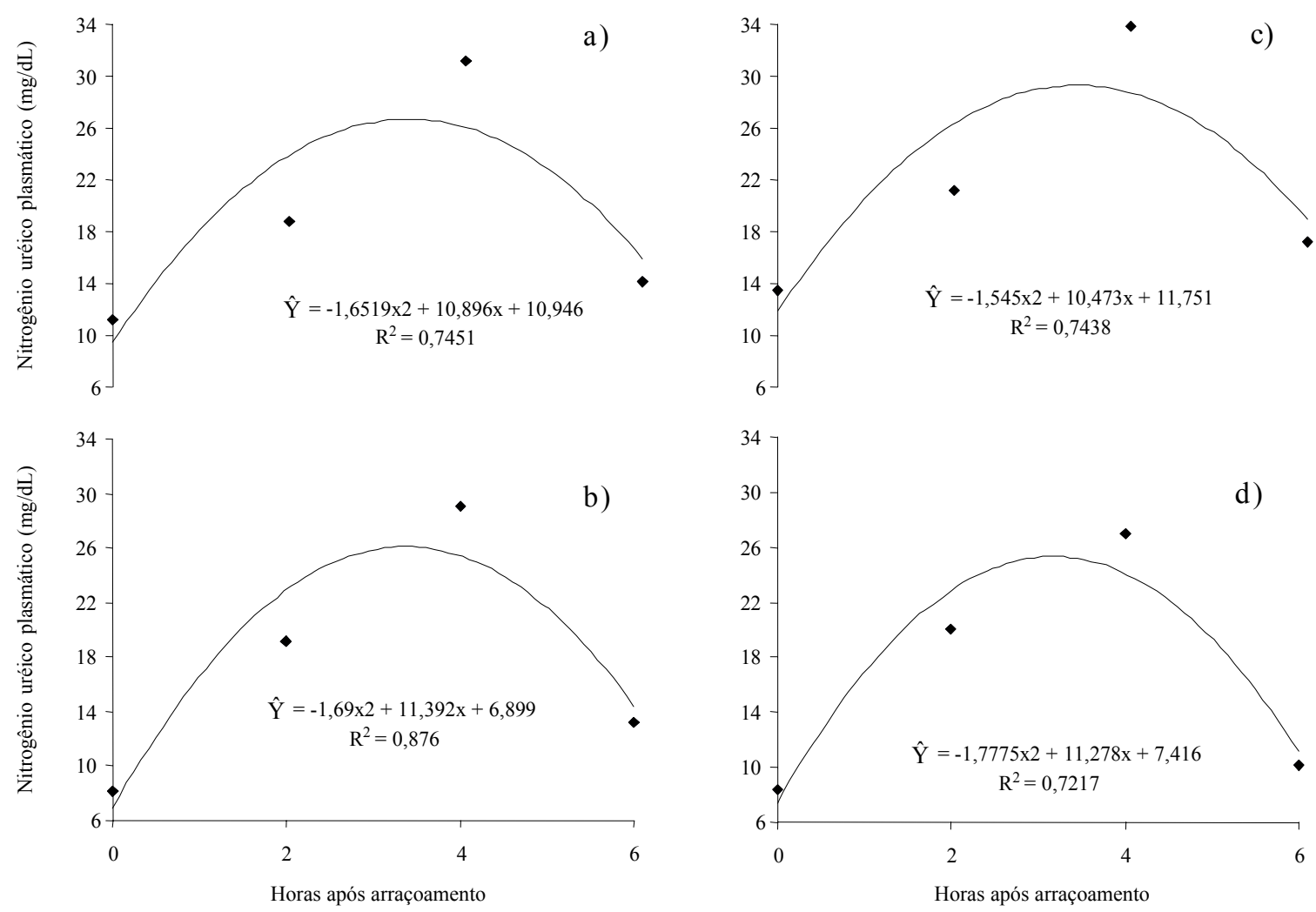

Figura 2 - Concentrações de N-uréico plasmático em búfalas alimentadas com diferentes fontes de lipídeos na dieta. a) sem lipídeo adicional, b) grão de soja, c) óleo de soja, d) caroço de algodão.

\section{Conclusões}

A utilização de grão de soja, óleo de soja e caroço de algodão como fontes de lipídeos em dietas para búfalas em lactação não influenciou o consumo e coeficiente de digestibilidade da matéria seca. Entretanto, as digestibilidades do extrato etéreo da dieta com grão de soja e das frações fibrosas da dieta com caroço de algodão foram as mais baixas. As fontes lipídicas testadas podem ser recomendadas para alimentação de búfalas em lactação, desde que respeitados limites máximos de extrato etéreo na matéria seca da dieta.

\section{Literatura Citada}

ABDULLAH, M.; NAWAZ, H; MOHIUDDIN, G. Effect of feeding different levels of supplemental tallow on the performance of lactating buffaloes. Journal of Animal Science, v.79, p.119, 2001 (suppl. 1).

ALLEN, M.S. Effects of diet on short-term regulation of feed intake by lactating dairy cattle. Journal of Dairy Science, v.83, p.1598-1624, 2000.

ASSOCIATION OF OFFICIAL ANALYTICAL CHEMISTS - AOAC. Official methods of analysis. 12.ed. Washington, D.C.: 1990. $1094 \mathrm{p}$.
BARTON, B.A.; ROSARIO, H.A.; ANDERSON, G.W. et al. Effects of dietary crude protein, breed, parity, and health status on the fertility of dairy cows. Journal of Dairy Science, v.79, p.2225-2236, 1996 .

BATEMAN II, H.G.; JENKINS, T.C. Influence of soybean oil in high fiber diets fed to non lactating cows on ruminal unsaturated fatty acids and nutrient digestibility. Journal of Dairy Science, v.81, p.2451-2458, 1998 .

BAUMAN, D.E.; LOCK, A.L. Concepts in lipid digestion and metabolism in dairy cows. In: TRI-STATE DAIRY NUTRITION CONFERENCE, 2006, Ohio. Proceedings... Ohio: Ohio State University, 2006. p.1-14.

BEQUETTE, B.J.; BACKWELL, F.R.C. Amino acid supply and metabolism by the ruminant mammary gland. Proceedings of Nutrition Society, v.56, p.593-605, 1997.

CANT, J.P.; FREDEEN, A.H.; MacINTYRE, T. et al. Effect of fish oil on milk composition in dairy cows. Canadian Journal of Animal Science, v.77, p.125-131, 1997.

CANFIELD, R.W.; SNIFFEN, C.J.; BUTLER W.R. Effects of excess degradable protein on postpartum reproduction and energy balance in dairy cattle. Journal of Dairy Science, v.73, p.2343-2349, 1990.

COCHRAN, R.C.; ADAMS, D.C.; WALLACE, J.D. et al. Predicting digestibility of different diets with internal markers: evaluation of four potential markers. Journal of Animal Science, v.63, p.1476-1483, 1986.

ELROD, C.C.; BUTLER, W.R. Reduction of fertility and alteration of uterine $\mathrm{pH}$ in heifers fed excess ruminally degradable protein. Journal of Animal Science, v.71, p.694-701, 1993.

FERGUNSON, J.D.; GALLIGAN, D.T.; BLANCHARD, T. et al. Serum urea nitrogen and conception rate: The usefulness of 
test information. Journal of Dairy Science, v.76, p.37423746, 1993.

HUNTINGTON, G.B.; ARCHIBEQUE, S.L. Practical aspects of urea and ammonia metabolism in ruminants. In: AMERICAN SOCIETY OF ANIMAL SCIENCE, 1999, Raleigh. Proceedings... Raleigh: North Carolina State, University, 1999. (CD-ROM).

JORGE, A.M.; ANDRIGHETTO, C.; MILLEN, D.D. et al. Desempenho e eficiência biológica de bubalinos de três grupos genéticos terminados em confinamento e abatidos em diferentes estádios de maturidade. Revista Brasileira de Zootecnia, v.35, p.252-257, 2006 .

LORENZONI, W.R.; CAMPOS, J.; GARCIA, J.A. et al. Ganho de peso, eficiência alimentar e qualidade da carcaça de novilhos búfalos, nelores, holandeses e mestiços holandês x zebu. Revista Brasileira de Zootecnia, v.15, p.486-497, 1986.

LANA, R.P.; CAMARDELLI, M.M.L; RODRIGUES, M.T. et al. Óleo de soja e própolis na alimentação de cabras leiteiras: consumo de matéria seca e de nutrientes e parâmetros de fermentação ruminal. Revista Brasileira de Zootecnia, v.36, n.1, p.191-197, 2007.

MERTENS, D.R. Analysis of fiber and its uses in feed evaluation and ration formulation. In: SIMPÓSIO INTERNATIONAL DE RUMINANTES, REUNIÃO ANUAL DA SOCIEDADE BRASILEIRA DE ZOOTECNIA, 29., 1992, Lavras. Anais... Lavras: Sociedade Brasileira de Zootecnia, 1992. p.1-32.

MERTENS, D.R. Predicting intake and digestibility using mathematical models of ruminal function. Journal of Animal Science, v.64, p.1548-1558, 1987.

NAWAZ, H.; ABDULLAH, M.; MOHIUDDIN, G. Effect of feeding different sources of supplemental fat on the performance of lactating buffaloes. Journal of Animal Science, v.79, p.119, 2001 (suppl. 1).

NATIONAL RESEARCH COUNCIL - NRC. Nutrient requirement of dairy cattle. 6.ed. Washington D.C.: National Academy of Sciences, 1989. $158 \mathrm{p}$.

PALMQUIST, D.L. Influence of source and amount of dietary fat on digestibility in lactating cows. Journal of Dairy Science, v.74, p.1354-1360, 1991.
PALMQUIST, D.L. Suplementação de lipídeos para vacas em lactação. In: SIMPÓSIO SOBRE NUTRIÇÃO DE RUMINANTES, 6., 1989, Piracicaba. Anais... Piracicaba: Fundação de Estudos Agrários Luiz de Queiroz, 1989. p.11.

PALMQUIST, D.L.; JENKINS, T.C. Fat in lactation rations: review. Journal of Dairy Science, v.63, p.1-14, 1980.

PEREIRA, C.M.A.; CASTRO, A.C.G.; SILVA, J.F.C. et al. Produção e composição do leite de vacas recebendo ração concentrada com grão de soja. In: REUNIÃO ANUAL DA SOCIEDADE BRASILEIRA DE ZOOTECNIA, 34., 1997, Juiz de Fora. Anais... Viçosa, MG: Sociedade Brasileira de Zootecnia, 1997. p. $262-264$

SILVA, M.M.C.; RODRIGUES, M.T.; RODRIGUES, C.A.F. et al Efeito da suplementação de lipídios sobre a digestibilidade e os parâmetros da fermentação ruminal em cabras leiteiras. Revista Brasileira de Zootecnia, v.36, p.246-256, 2007.

SILVA, M.M.C.; RODRIGUES, M.T.; BRANCO, R.H. et al. Suplementação de lipídios em dietas para cabras em lactação: consumo e eficiência de utilização de nutrientes. Revista Brasileira de Zootecnia, v.36, n.1, p.257-267, 2007.

SILVA, M.M.C.; RODRIGUES, M.T.; BRANCO, R.H. et al. Suplementação de lipídios em dietas para cabras em lactação: consumo e eficiência de utilização de nutrientes1. Revista Brasileira de Zootecnia, v.36, p.257-267, 2007.

SNIFFEN, C.J.; O‘CONNOR, J.D.; Van SOEST, P.J. et al. A net carbohydrate and protein system for evaluating cattle diets: II. Carbohydrate and protein availability. Journal of Animal Science, v.70, p.3562-3577, 1992.

UNIVERSIDADE FEDERAL DE VIÇOSA - UFV. SAEG - Sistema de Análise Estatística e Genética. Viçosa, MG: 1997. (CD-ROM).

Van SOEST, P.J.; ROBERTSON, J.B.; LEWIS, B.A. et al. Methods for dietary fiber, and non-starch polysaccharides in relation to animal nutrition. Journal of Dairy Science, v.74, p.3583-3597, 1991.

VILELA, D.; ALVIM, M.J.; CAMPOS, O.F. et al. Produção de leite de vacas holandesas em confinamento ou em pastagem de coastcross. Revista Brasileira de Zootecnia, v.25, p.1228-1244, 1994. 